\title{
Caducifolia: Las hojas que se lleva el viento (I parte)
}

- Ratael Rodriguez Díaz

A Ana Belki

\section{Ilasta la más sencilla flor en el camino}

merece toda tu atención de poeta.

\section{Poemas para que los lleve el viento}

Los sábados, antes de reunirnos en "Papeles de la tertulia" - (irupo I iterario que funcionó desde 1986 a 1996 , teniendo como núcleo fundamental de asistentes a la familia Morales: Ricardo Morales padre, Ricardo hijo, Laura de Pardo, Pablo y David-, Luisa y yo dábamos un paseo por los jardines de la UCA. Uno de esos sábados, bajamos caminando desde la biblioteca hasta llegar casi a la cancha de fútbol (un recorrido de unos $30(0)$ metros); cuando ya ibamos de regreso para la biblioteca, pasamos junto a la parte trasera del edificio de rectoría. Ahí, en los jardines interiores, tras de los muros de ladrillo visto, hay un árbol de fuego enorme; por ser época de verano, el árbol no tenia ni una sola hoja.

—Mirá ese árbol; parece que está completamente seco_, me dijo Luisa, en un tono de casi lamentación... Casualmente, en esos días yo había consulado un libro de Itistoria Natural, en busca de mayor claridad sobre el lema ése de la caída de las hojas en los árboles. Así que yo tenía muy fresca la información consultada, y pude soltarme con una cáledra sobre ese lema...

“-No, Luisa, esc árbol no está muerto... No se ha secado. Lo que pasa es que pertenece a las especies de árboles caducifolios; es decir, árboles que pier- 
den completamente sus hojas durante el verano para nosotros. durante el invierno en los países templados y fríos. Fsa es la manera que tienen de defenderse: Sin hojas, consumen mínimamente agua y oxígeno... Distinto es el caso de los perenniloliosミ esos árboles si conservan sus hojas durante todo el año, incluso bajo condiciones extremas; asi ocurre con los pinos y sus parientes como las araucarias, los cipreses y otros".

“- ¡Oué interesante!; fijale que yo no sabía nada de esas diferencias entre los árboles. ¡Por eso, yo creí que el árbol de fuego se había secado!”

"-Bueno, la cosa es que precisamente en estos días yo he estado pensando en cómo se interrelacionan los seres y objetos de la naturaleza... Por ejemplo, hay semejanzas entre las hojas de un árbol y las páginas de un libro. Decimos "hojear" un libro cuando hacemos pasar rápidamente sus páginas ante nosotros, como si lueran las hojas desprendidas de un árbol, y movidas rápidamente por el viento... Así que a un poemario mío le voy a litular (Aouch(o).on, por(que va a consistir de poemas escritos en páginas sucltas y reunidas en un dossier, sin empastar. La temática scrá ecológica y amorosal a la vež".

“-Nunca me hubiera imaginado que estuvieran relacionadas las hojas de un árbol con las poesías".

Mientras así hablábamos, ya habiamos llegado Luisa y yo a la entrada del parqueo de la biblioteca. Fue en ese momento en que senti más que vi una hoja de papel blanco que fue a cacr exactamente a mis pics. La primera impresión fue que se trataba de un papel cualquiera llevado por el viento; pero me dio por inclinarme para ver con más atención de qué se trataba. Y ahí estaba... era el forro o portada retirable de un libro: Mao Tse -Tung. Pocmas. Maravillado, no me quedó más que decir a Luisa: "— ¡Ya ves que los poemas son hojas que se lleva el viento!"

Recogí con casi veneración el forro-carátula y traté enseguida de encontrarle una explicación lógica a lo que acababa de suceder... Estábamos a unos treinta o cuarenta metros de la entrada de la biblioteca.

"-Fijate, Luisa, que ahora me acuerdo que durante estos días pasados, las empleadas de la biblioteca estuvicron limpiando libros y más libros... Quizá entonces se voló esta cubierta, y de vuelta en vuelta, el viento la ha venido a depositar ahora aquí, a mis pies".

Al lunes siguiente fui temprano a la biblioteca, con el objetivo de devolver el forro, para que pudiera ser restituido al libro correspondiente. Pero, para acrecentar mi sorpresa, en la biblioteca no estaba el libro: Mao Tse-Tung. Pocmas. Tampoco estuvo nunca ahí: No es que, estando en la biblioteca, alguien se lo hubiera robado, o que durante los días de la limpieza, a alguna empleada se le hubiera extraviado. Simplemente, ¡no existía registro de tal libro! ; así que Mao 
Tse-Tung. Poemas. Había llegado a saber desde dónde, justo para corroborar que los poemas, la poesía son sólo hojas que se lleva el viento... El símbolo, además, podía tener una aplicación altamente dramática: Mao Tse-Tung y su revolución cultural china, ya son historia. Toda la poesía que se pretendió atribuir a aquel acontecimiento histórico, es ya sólo una hoja que el viento deposita a los pies de una persona.

En esta ocasión, transcribo algunos poemas que formarán parte del libro Caducifolio. Ellos están titulados como "Hoja No. 1, No. 2, No. 3..."

\section{HOJN N ${ }^{\circ}$}

Hundo mis ojos

Tierra adentro

manos

dedos escarbando

cayendo en descenso

vertical

las redes capilares

las vibrisas

los peciolos huscando

la fuente nutritiva

los jugos sabrosos

suculentos.

Después de tanto tiempo

Mis raices

Han de estar hurgando

Nutriéndose

En el magma.

Porque son

puro volcán

mis floracione's.

Coducifolio: Los hojos que se llevo el viento 


\section{Hoja $N^{\circ} 2$}

: Flor en cela

atraen tus pistilos

a todos los insectos

$$
\begin{aligned}
& \text { abejorros } \\
& \text { colibries } \\
& \text { saltimbanquis }
\end{aligned}
$$

$y$ poetas

polinizadores

del mundo.

\section{HoJn $N^{\circ} 3$}

Quizás nunca

llegará a saber la flor

que por ella

el árbol empezó a holar sus hojas

y quedó expuesso

a la intemperice

de las risas

de los transcúntes.

Sus ramas ridiculas

al aire

sus huesudos miembros

su caricaturesca contorsión.

Da lo mismo quizás

Que el árbol nunca llegue

Al roce

De la flor

Aunque por ella

La fábrica guardada en la corleza

irá transfigurando

savia en miel.

Por ella

Los versos volátiles

Gaseosos

Irán oxigenando

Sus sueños de botón. 


\title{
$\operatorname{HoJA} N^{\circ} 4$
}

Hasta la más sencilla flor

silvestre del camino

merece toda tu atención

de poeta.

\section{Hกנ^ $N^{\circ} 5$}

Aqui

desde esta altura

te sigue en volandas

planeando

mi ilusión.

\author{
Abajo \\ falda al aire \\ te me vas \\ yendo \\ y ocultando \\ Hasia que quedan solos \\ los patios y las hancas \\ el árbol y el farol \\ y solos los lugares \\ que recorrimos juntos \\ mi loca fantasía \\ y tu desdén \\ tu irashumante \\ olor.
}

(Marzo de 1992).

Ahora bien, la magia de estas cosas no para, una vez echada a andar; así es que por esos mismos días en que me ocurrió lo del lorro-carálula de Mao, lambién se dio otro hecho "casual", de la misma especie que el anterior...

Con Oscar Edgardo Melhado teníamos a nuestro cargo un programa radial en YSUCA, Flor y Canto. Como en el programa hablábamos de cultura y poesía, pues yo conté en una edición de Flor y Canto, la maravillosa experiencia que tuve con Luisa en torno a la pocsía "CADUCIFOLIA". En esa oportunidad, Edgardo recalcó: "- - ssí son los milagros que ocurren en el ámbito de la poe- 
sía, y no es de extrañar que a cualquiera de los oyentes del programa pueda ocurrirle algo similar".

Pero fue al mismo Edgardo a quien le ocurrió, eso mágico, unos días después de que pasó al aire el programa mencionado. Él mismo se encargó de relatar la experiencia a los oyentes de Flor y Canto: “- Acababa de parquear mi automóvil, cuando me di cuenta de que las heces de un pájaro ensuciaban el capó del vehículo... Casi sin pensarlo, busqué en los alrededores inmediatos algún papel o trapo con que poder limpiar la suciedad... Entonces, ahí, en el suelo, junto a una de las Ilantas delanteras, estaba el papelito que habría de servirme... pero, al levantarlo, me di cuenta de que era un recorte de período que contenía un soneto a la rosa... Hasta ahora no sé quién es el autor; a mí me suena a Oswaldo Escobar Velado... Lito cree que puede ser de Roque Dalton. Bueno, lo cierto es que llegó hasta mí en alas del viento; igual que llegó hasta Lito el forro-carátula de los Poemas de Mao".

En esta ocasión voy a transcribir el poema-hoja-al-viento que Oscar Edgardo Melhado conserva como una reliquia en su billelera. Como el recorte está baslante deteriorado, luvimos que hacer casi una labor de paleografía o reconstrucción de aquellas partes del texto pasibles de la reconstrucción, dejando en blanco aquellas otras que fue imposible reconstruir.

LA ROSA TSS ISTA I.UI(MIBRI:)

La rosa es esta lumbre memoriosa un asombro en el sueño)

(per) seguido

( er)ca en la mano retenido

( ) tarde on noche silencio(sa).

(Ma)ñana que irradia luz airosa

de la que se diria ha

desprendido

(cl) aroma en su jugo consiumido)

creciendo sohre el tallo,

(d)espaciosa.

La rosa cestá e’n aro(ma)

sustentada

y es tal su suave mundo de

sencillo

que con mirarla cueda transformada 


\section{en un fulgor de lámpara de \\ utrillo \\ en una fuente de agua y sol \\ colmada \\ en blanco o en carmin con \\ amarillo.}

\section{EI balcón en el castillo}

En anteriores escritos he explicado cómo se hace presente en mí la persuasión de ser alguien privilegiado, y cómo esa convicción está vinculada a la posesión de mi arboleda de Antiguo Cuscatlán. En este capítulo continuaré explayándome sobre el tema.

La posición del terreno y la disposición de los árboles y plantas permiten que uno se ponga a "ensayar" perspectivas difcrentes para enfocar las cosas. Contaba yo en otra parte cómo tengo un sitio preferido desde donde se ve casi toda la arboleda: A lo largo y ancho, arriba y abajo. Pero se me ocurre ahora relatar lo que he estado haciendo recientemente: tomar conciencia de cómo se ve todo de diferente si se sube uno al techo de la casa, o se agacha uno hasta casi ver todo a ras de suelo.

Subido en el techo se tiene una visión casi completa del Valle de Las Hamacas, donde está asentada San Salvador; casas y edificios se van encaramando cada vez más arriba en las faldas del volcán de Quezaltepeque, mientras que en dirección norte, casas y más casas se pierden hasta casi topar con el cerro de Guazapa. Más allá, en el fondo azulado, las montañas de Chalate y algunos cerros de Honduras... Definitivamente, estamos en un lugar elevado. Con mi hijo Cayo hacíamos, hace poco, un cálculo de la altura en que estamos: " "-Desde el centro - Catedral, pongamos por caso-, tenés que subir y subir, hasta llegar al bulevar de los Próceres; de ahí, seguís subiendo hacia la autopista sur, hasta llegar a la torre Cuscatlán... y mirá cómo tenemos allá abajo esa torre. Yo creo que estamos a la misma altura del asta esa que tiene la luz roja intermitente... Total, estamos bien alto, en las colinas de Antiguo Cuscatlán. Y si el centro de San Salvador está a unos doscientos metros del nivel del mar, nosotros quizás ya estamos llegando a los mil metros... exagerando, claro".

Como diversión, en la noche me gusta distinguir, entre las lucecitas de allá abajo, algunos rótulos luminosos ya conocidos; así, un centro de diversiones para niños, llamado Mundo Feliz, deja ver apenas sus letras azules, al lado de la silueta, en un rojo también luminoso, de Mickey Mouse, diciendo adiós. Cerca, un rótulo de Coca Cola se va encendiendo paulatinamente hasta quedar completo: letras rojas sobre un fondo celeste... Y como el lugar donde están esos rótulos es cerca de la casa de mi mamá, en la colonia Yumuri, entonces yo 
puedo viajar con la vista y con la imaginación unos siele kilómelros, en línea recla y hacia abajo. De hecho, desde la casa de mi mamá, las colinas donde se encuentra mi arboleda se ven en dirección sur, conlormando una silueta de color azul oscuro."

También yo veo las partes más altas de las colinas de Antiguo ('uscatlín. Sólo que las tengo lan próximas que casi puedo tocarlas: til (erro de "til CabaIlito" me regala con los verdes más intensos; más atrás de él, el verde se va convirtiendo en celeste, según los cerros se me vayan alejando, o según la hora del día... Espectáculo fascinante es ver, a buenas seis de la mañana, las bandadas de pericos que hacen escala en las harrancas y hondonadas de esos cerros, antes de partir en grupos bulliciosos hacia sus comederos cercanos a las costas. Cuando los puntitos oscuros se pierden en la lejanía, me gusta imaginar que me voy viajando con ellos... como viajar quisicra también con las bandadas de palomas silvestres —ala blanca o mustugonas, no sé- que viajan en la misma dirección de los pericos... También ellas, como los pericos, retornan en grupos — silenciosos, los de las palomas- a sus dormideros... ^ veces, en las tardes, me entretengo también contemplando a esos cotidianos peregrinos.

Así pues, desde el techo o desde la terraza que se extiende a lodo el firente de mi casa, lenemos una vista privilegiada: la ciudad capilal, las colinas rebosantes de verdor y las casas arracimadas de las colinas recién urbanizadas de Anliguo Cuscatlán. Corona el privilegio la visión nocturna de las conslelaciones. Desde un lugar estratégico de la terraza, en que colocamos una hamaca, puedo apreciar en todo su esplendor a Orión elevándose jusio enfrente de nuestra casa.

Durante las noches especialmente despejadas de verano, puedo seguirle el curso a muchas otras constelaciones: las (Osas Mayor y Menor, el l cón, ('asiopea y Cefeo... Y uno de los momentos más emocionantes es descubrir la ('ruz. del Sur, brillando a todo dar durante la madrugada, rodeada casi completamente por el Centauro y su rutilante estrella Alfa, distante de nosotros sólo cuatro años luz. o cuatro billones de kilómetros(!!!)... Pero mi experiencia personal con las estrellas es tema de otra serie de escritos.

La sensación que tengo a veces $-y$, curiosamente, una idea parecida comentó Panchí, mi ex esposa - es la de estar asomado a un amplio balcón en la muralla almenada de un castillo. De hecho, a mí me gusla fanlascar imaginandome todo un señor castellano, o un señor leudal que tiene a sus plantas la villa y sus villanos. Yo sé que eso es pura lantasía: pero como yo vivo las melíloras, la poesía y lo mágico como dimensiones de lo real, entonces, la persuasión de estar contemplando lodo desde la superioridad de un castillo, da cuenta de cómo me siento en el fondo. Coneclado con lo anterior está el tema de los árboles y plantas de mi arboleda; porque el tipo de relación que tengo con el reino vegetal marca -entre otras cosas- mi diferencia respecto de la mayoría de mis congéneres, sobre todo de este país. 
Sé que estar atento y pendiente de cómo van creciendo o lloreciendo árboles y planlas, es una suerte de ejercicio y adiestramiento para mis sentidos "externos" e internos. Ejercicio que me prepara para captar malices en formas, colores $e$ intensidad de vibraciones que provienen de seres animados, lanto como inanimados. Por ejemplo, la provisión de orquideas "huérfanas" que ahora lengo, recibe como las otras plantas y llores "de abolengo", el mismo tralo "personalizado" (ya volveré más adelante sobre este punto). Algunas malilas de mis "hućrfanas" ya han llorecido: su llor es pequeña y bonila: hlanca, con ray itas rosadas en su interior. Pero no es una llor conspicua... sin embargo, la manera en que las he distribuido, destaca su sencilla belleza; asi, hay un tronco pequeno cuajado de esas orquideas; lo he colgado con alambre de la rama de un árbol, de manera que parece un bouquet de lilorcitas silvestres. Y yo le digo a (ayo: "Fijale: estas 17orcitas son sencillas, pero la disposición en que están (la allura, el lugar destacado) las realza definitivamente; son plebeyas, pero yo las tralo como si lueran princesas... Asi ocurre con algunas muchachas: son muy sencillas y pueden ser hasta ordinarias, pero uno debe hacerlas sent ir como si lueran lo más importante en la vida de uno, y que deben ser reverenciadas como si lueran reinas.

Hay ciertas orquideas que, en la arboleda, florecen escondidas entre el ramaje; y no son precisamente microscópicas. I a bonita laclia rubescems-o vara de san José, como yo la llamo, por su color blanco y su forma de azucena- es una de tales. Pero se trata como de un capricho: sorprenden y agradan a la vista, pero solo a quien se toma el trabajo de llegar hasta ellas, apartando ramas y hojas; para el resto, pasan desapercihidas... Yo creo que es algo así como las flores que sólo se dan el las altas montañas - la Edelweiss, por ejemplo-: únicamente pueden ser contempladas por los osados escaladores que dan con ellas. Su belleza constituye algo asi como un premio al esluerzo, a la voluntad de ser diferente... Del mismo género de llores retadoras considero yo a mis laelia rubescens, porque a algunas de ellas puedo descubrirlas escondiditas entre la fronda, mientras estoy regando, durante los meses de noviembre y diciembre.

Ouiero explicar ahora en qué consiste el trato "personalizado" que yo les doy a mis árboles y plantas: limpiar las hojas secas de las matilas de orquideas es una labor minuciosa; debo hacerlo cuidando de no arrancar alguna hoja sana o algún botón. También presto alención a cómo se van extendiendo las raices, o si no le cae bien a la planla el silio donde esta... Pero es la regada, casi diaria, la que me lleva más liempo y alención; puedo decir que riego "a conciencia": cuidando de que no quede sin mojarse ningún rincón. Porque cierlas orquideas y helechos, por estar bajo la sombra de algunas hojas grandes de filodendros, no reciben la necesaria ración de agua, incluso durante la época de lluvias. Por eso, debo regar árbol por árbol, arriate tras arriale y casi malita a malita de orquideas. El hecho es que dejo empapado todo el follaje, de arriba abajo; tanto como permile la fuerza del agua en la manguera. Yo diría que riego como si esa fuera 
la última gran rociada de agua que hubicran de recibir en su vida los árboles y plantas de mi arboleda.

Podría dar una "media regada”, como para salir del paso ("-Mañana ricgo más a fondo"..."), pero eso no me de jaría tranquilo porque scría como haberles fallado a mis árboles y plantas. $Y$ eso no me lo puedo permitir... Bucno, mi interlocutor interno no me dejaría hacerlo. "-¡^sí debe ser, y punto!” es un imperativo que también acciona en los otros ámbitos de mi vida; por ejemplo, preparar clases es algo que me exige cuidar los más mínimos detalles, a pesar de que haya dado ese tema varias veces y de que sean pocos los alumnos... Igual me ocurre con la corrección de textos que acepto por encargo: No debe escapárseme la más mínima falta. ¡Mi nombre y mi imagen están empeñados en esa labor!

El descuido en ese campo de la corrección de los textos (el tomo I de Ilistoria de El Salvador está plagado de monosílabos acentuados: dio, vio, fuć.....) da la impresión de que para los responsables esas fucran minucias... Para mí, en cambio, son cosas trascendentes: no por la falla en sí (a cualquicra se le escapa un error), sino porque el texto en cuestión llega a otros lados: Ilistoria de El Salvador_tuvo una edición de 150,0(0) ejemplares y fue impreso en México. Y bien podría concluirse con razón: “- “- Cin Salvador estín muy alrasados en cuestiones de ortografía: todavía siguen acentuando los monosilabos, como hace 5() años..."

El maestro de obras que me hace trabajos de albañilería en la casa es bastante bueno (considerado en los gastos; efeclivo, a pesar de la rapidez con que trabajan él y sus ayudantes). Pero no deja de escapárscle alguna chapuza; por ejemplo: va dejando restos de cemento sobre los ladrillos, ya fijados, o no lira bien rectas las líneas de ladrillos, o no quedan bien al ras las lajas... Alguna vez. que yo le reclamé, me respondió un poco molesto que yo debía ayudarle a completar esos detalles. "-Precisamente, le dije-, Ud. tiene que entregarme una obra totalmente acabada y afinada, para que yo le siga encargando trabajos. Si no, es como si a mi me ocurriera entregar un escrito todo lleno de tachaduras y faltas de ortografía... Muy probablemente ya no me encargarian otro..."

En gran parte, creo que eso pasa a nucsiros obreros y aun a nucstros profesionales: los detalles del acabado son para ellos "minucias sin importincia", defectos "microscópicos" en los cuales es ridículo reparar, porque sólo los licnen en cuenta personas puntillosas y exageradas... Pero yo creo que es ahí donde se da la diferencia entre la persona desarrollada y la que no lo es: en ese afán perfeccionista, en ese prurito por el delalle mismo: porque ese afán de cuidar hasta en lo más mínimo lo que uno está haciendo es rellejo de una estricta disciplina interior, de una alta estima respecto de la ocupación o trabajo propios; una responsabilidad cósmica — diría yo—, porque lienc a la base la convicción de que la obra de uno ha de perdurar por los siglos de los siglos. 
Con mis vecinos tengo problemas por mis árboles. Uno de mis vecinos del costado norte es un ingeniero civil, muy buena gente, pero con quien me veo muy poco. El otro día, sin embargo, la esposa del ingeniero me pidió muy amablemente que mandara a cortar las ramas de un Arbol de Fucgo, las cuales están sobre el lecho de su casa. Argumentó que las hojas pépueñilas del árbol laparen los canales y que durante una de las últimas tormentas, la casa se le inundó de arriba abajo... Yo le promelí que, cuanto antes, mandaría a corlar esas ramas molesias.

El vecino del costado poniente sí es más folklórico: ya desde hacia tiempo me venía diciendo que corlara unos árboles de jocote que lienen ramas y raíces invadiendo su propiedad. Pero hace unos pocos dias lue tajante: "- I)on I.ilo, esos árboles suyos me le dan demasiada sombra a mi terreno; ¿no podría mandar a podar esas ramas? Además, esos palos de jocole no sirven para nada... Sólo las ardillas se comen la fruta..." le respondi que dentro de poco llegaría el "miquero" a podar y "ralear" todos esos árboles que a él lanto le molestan... Pero me estoy reservando para el momento oportuno el comentario (jue, creo, mi vecino se merece: él no aprecia la frescura que dan los árboles; prefiere emplafonar su terreno y morirse de calor...

Se me ocurre que ninguno de esos vecinos me ha lelicilado por lo hermoso que se ven los árboles, o por la música tan relajante que se escucha cuando suena el viento entre las ramas. Al contrario, pareciera (jue estin al acecho para reclamarme por el peligro que implica tener árboles lan allos, por la hojarasca (auncue sus terrenos estén llenos de cachivaches y hasla ripio y basura), por los zancudos que se crían en la humedad, por lanla sombra, elcétera... I)elinitivamente, los árboles son para ellos una presencia molesta - a la vista, al oído y quizás a lodos los sentidos- y yo me evilaría problemas si mandara a corlarlos todos. Muy probablemente entonces, si me lelicitarian efusivamente. Porque al lin habría tomado una medida sensala..

Pareciera, pues, que deloo andar pidiendo disculpas a lodo el mundo por esta mi loca afición por plantas y írboles. ts un hecho: tenemos una valoración distinta de las cosals mis circunvecinos y yo. Pareciera (jue. aunque ocupando el mismo espacio físico, habláramos idiomas diferentes y habitiramos en dimensiones radicalmente distintas de la realidad.

Una de las experiencias interesantes lambién en lo que loca a las perspectivas consiste en tratar de ver las cosas, ya no desde arriba ---desde el techo-. sino desde abajo. Sentarse en el suelo en medio del patio o agacharse hasta casi ver lodo a ras de piso, hace descubrir lormas y aun colores insospechados. Algunas hojas se ven especialmente grandes, hasta gigantes, se podria decir; así, las hojas quequeishque, las mano-de-león o las de piñanona. Los arriates de ladrillo parecen murallas en miniatura, los enlajados y enladrillados se me antojan a veces calles y avenidas a pequeña escala. Total, que tomar esa perspectiva 
equivale a convertirse prácticamente en gnomo, en duende de esos que, se supone, miden unos $20 \mathrm{cms}$. de altura, habitan en promontorios de piedra, calzan zapatitos diminutos de unos 5 o $6 \mathrm{cms}$. de largo, y que sólo pueden ser vistos por quienes tî̀enen los ojos abiertos para percibir la suprarrealidad

Por andar hurgando debajo de las hojas y por recorrer casi diariamente los rincones de mi terreno, me he dado cuenta de presencias y de ausencias Ilamativas... Un amigo me había dicho que en ciertas orquídeas vive cierta especie de hormigas: dentro de las macollas húmedas de la epífita hacen sus nidos esos insectos, pero no destruyen la planta anfitriona; simplemente, la utilizan como refugio, dormidero o cuartel.

Hace unos días pude comprobar lo afirmado por mi amigo... Me llamó la atención cómo duraban dos vainas donde deposita sus semillas una catleya skinnery o San Sebastián (la guaria morada, para los licos). Las diminutas semillas habían salido esparcidas como polvo, hacía ya varios meses; y, sin embargo, las cápsulas enormes ya secas y semiabiertas habían quedado pendienIes aún de la planta. Cuando reparé en el delalle me dije: “- bueno, si y a no hay semillas aquí, ¿,por qué esta San Sebastián no se deshace de esta fea cápsula..., clla tan vanidosa y tan pendiente de su belleza?" Entonces, al empezar a retirar la cápsula en cuestión, me di cuenta de que en clla tenían todo un almacén de huevos unas hormigas negras, un poco más grandes y rechonchas que las hormigas comunes; de color negro mate y, sobre todo, inofensivas en todo sentido: no pican fuerte, ni hacen grandes promontorios de ticra, ni devoran las hojas de las plantas. Son de una especie de hormigas habituales por estas partes; cllas caminan en hileras poco numerosas, $y$, hasta ahora, no sć de qué sc alimentan, porque yo no las he visto nunca acarreando hojas, o insectos muertos, o migajas de pan... Pero lo interesante fue constatar que son ellas las hućspedes de las orquídeas anfitrionas... A ver si en adelante descubro más de esos singulares nidos.

Las Mariposas Monarca visitan mi terreno durante los últimos meses de invierno - agosto y septicmbre-; sus danzas y piructas aćrcas llamaban mi atención desde hacía mucho tiempo. Pero fue hasta este año que una amiga me hizo ver que se trataba, precisamente, de la especie de Mariposas Monarca: esos lepidópteros tan curiosos porque vienen en migración desde el norle-desde México o más arriba aún-. y vuclven luego después de haber recorrido casi toda América. Según me recordaba un alumno, Arturo Farfán, es la quinta generación de Mariposas Monarca la que retorna a su lugar de origen... Tanto liempo vićndolas, y no sabía de sus costumbres y de su prosapia... Siempre queda tanto por aprender.

En todo caso, ver la realidad circundante - mayúscula o minúscula, natural o social- desde la superioridad de un altozano, es algo que marca la radical diferencia entre quien quiere vivir hermanado orgánicamente con su medio, y aquel otro que sólo utiliza ese medio como pista de aterrizaje para sus "altos 
vuelos", lugar de paso, y, en último término, como “piso”, tal como explicaba antes.

Porque este país a punto de ser convertido en un inmenso dormitorio para quienes sueñan con despertarse trabajando en el norte; a punto de metamorfosearse en una gran zona franca, donde hasta los maestros e intelectuales sean instructores de futuros maquileros; este país que ya se acerca al ideal utópico de ser todo él una supercarretera, es aún un reservorio de vida natural, sana y fresca para quien sabe acercarse y beber de sus fuentes.

\section{Un país que se rehusa a morir}

El Salvador, el antiguamente llamado Cuscatán o Cuscatlán, ha sido un país extraordinariamente fértil debido a la presencia de grandes cantidades de ceniza volcánica, la cual es a largo plazo un, extraordinario nutriente de la lierra. Aunque siempre muy poblado, el actual El Salvador habia conscrvado hasta hace poco tiempo bastante de su vegetación originaria. Han sido las generaciones últimas de salvadoreños las que, llevadas por una voracidad sin límites, han destruido bosques, contaminado ríos y no dan muestras de querer parar ese proceso destructivo. El símbolo más patético de todo esto es el río que atraviesa, como una columna vertebral, la ciudad capital: cl río Acclhualc. Etimológicamente Acelhuate significa el río de las ninfas; y, efectivamente, hasta hace poco tiempo estaba cubierto de esas hermosas plantas acuáticas, y podían encontrarse peces y cangrejos en su cauce... En la actualidad, recordar eso causa risa porque ahora el Acelhuate es la gran tubería natural para las aguas negras, y lo que menos hay son peces y ninfas.

Pero El Salvador es un país que se empeña todavía en producir vida, por lo menos en la misma proporción en que los salvadoreños se empeñan en destruirla. El peligro está en rebasar los límites de ese poder reproduclivo de la naturaleza, de manera que el recurso (agua, launa, Пlora) ya no sea más renovable. sino que se haya perdido para siempre. Mucho me temo que si la presión continúa, ese será el destino de absolutamente lodos los re cursos naturales en El Salvador... Por ahora, todavía hay algunos reductos esperanzadores a los que debemos aferrarnos quienes hemos apostado por la vida.

El torogoz (momoto común) es un pájaro en peligro de extinción entre nosotros. Sin embargo, en mi arboleda pueden verse varios. Muy probablemente sus nidos los tienen en el paredón que de mi terreno da a la propiedad de los jesuitas. El hecho es que los vemos volar y cazar a todas las horas del día. Aunque hasta hace poco, pensábamos que se trataba sólo de uno o dos individuos, la sorpresa fue cuando Cayo descubrió a varios torogoces más; la ('ancla no había querido comer esa mañana y la comida permanccía en el plato, justo enfrente del apartamento de mi hijo. Como Cayo estaba entregado a su estudio, no reparó en lo que estaba pasando alrededor del plato de comida, hasta cue un 
revuelo lo sacó de su concentración: enfrente suyo, a pocos pasos, seis torogoces subían y bajaban disputándome la comida de nuestra perra. Dice Cayo que fue un espectáculo único: toda la belleza de esos pájaros desplegándose delante de él; gratuitamente y al por mayor ... En consecuencia, yo he pensado que a nuestra arboleda podríamos llamarla también El reino del torogoz.

Ya sólo ahí en ese trozo casi insignificante de universo, que es mi arboleda, puedo casi palpar el hálito de vida; no digamos en otros lugares más densamente arbolados o con cuerpos de agua del país: ahí "brota" la vida como por arte de magia. Y esa va a ser una de las explicaciones (que abordaremos más adelante) de por qué antes había más duendes, "sustos" y aparecidos. Pero por ahora me centraré en explicar la experiencia casi táctil del aliento vital.

Ciertas noches, mientras estoy regando, dirijo la vista a la luz de los lanales que alumbran el patio interior de mi terreno; pero no los veo directamente, a contraluz de troncos, ramas y hojas de algunos árboles. Entonces, la luz proveniente de los laroles toma un color blanco azulado: una especie de nubosidad muy tenue que flota en todo el ambiente... jelaro que se trata de la humedad producida por la vegetación y acentuada por las pequeñísimas gotas de agua que va produciendo la regada! Pero no es sólo eso... la delgada capa de vapor de agua lambién penetra la piel y se percibe a lo largo de todo el cuerpo como un friíto agradable... Yo digo que es el aliento de vida emanado por mi arboleda; y no puede ser otra cosa, porque a mi me llega como satislacción prolunda. Ealla no es sólo física (captada - como dije-como lirescura cue invade los pulmones y aun todos los poros), sino lambién espiritual, porque se transforma en un íntimo gozo por sentirse con vida, con ganas de cantar, saltar y hasta gritar; aunque también de recogerse y meditar para agradecerle a la vida por sentirse saludable y lleno de vigor.

Ahora bien, ese hálito vital -como el que Carpentier descubría permeando todas las selvas de América- es también algo tan denso (jue incluso la luz de mi lámpara de mano lo hace evidente y lo "retrata". Ya que él es como el ectoplasma, la película (en los dos sentidos: como delgada piel que cubre un cuerpo y como celuloide para caplar imágenes) mediante el cual se proyecta y hace visible (y aun tangible) el "alma” de mi arboleda... esa dama que me deja ver el tul de su ropaje durante cierlas noches, especialmente aptas para la confidencia... Ese espíritu que he logrado apresar en mi laboratorio-arboleda y que es, en última instancia, el aliento germinal y creador del país entero; espíritu a punto quizás de convertirse en vaho errante, en un alma mis en pena, porque le habremos arrebatado ya pronto el sustentáculo material y orgánico (jue toda alma necesila...

llace muchos años habia en el costado norponiente de la UC'A un terreno baldío que después llegó a ser propiedad de la universidad, y en el que actualmente se construyen los edilicios que albergarín la carrera de Ciencias de la 
Salud y las maestrías. Pues bien, en ese terreno había zacatales que eran refugio de conejos, culebras y pájaros de varias clases. Una vez, en la década de los 70, descubrí una presencia familiar en aquel terreno... Daba mi clase en un aula del edificio "A" cuando oí un canto que yo conocía bien. Como durante algún tiempo yo fui cazador, podía distinguir claramente el silbido de la codorniz: y allá, a unos metros de dislancia, una codorniz me saludaba con su "Fu-Fuit". Recuerdo que, emocionado, suspendí por un momento la clase, para explicar a los alumnos de qué se trataba. Yo sentí que me vieron extrañados, respeluosos pero extrañados: - ¿En que mundo andará este nuestro profesor?"

Días despućs, fui descubricndo que en toda esa zona de los alrededores de la UCA (sobre todo al costado poniente, donde había zacatales y monte próximos a una barranca, cerca de donde hoy está la torre Cuscatlán), había handadas de codomices... Cierto día, subiendo en mi jeep Suzuki por una calle que rodea a una colina cercana, levantó vuclo raudamente una handada de veinte o más codornices... Pasaron los años, y los silbidos de esas aves se fueron apagando. Hoy, probablemente, no queda por todo eso ninguna codorniz.

Sin embargo, frente a la mencionada lorre Cuscallán, hay un paredón singular: ya un vigilante de la UCA me había hecho nolar: "-Fíjese en la cantidad de cuevas que se ven en ese paredón. Allí han habilado hasla hace poco liempo lacuacines y gatos de monte (en realidad el zorro gris)". Ese mismo vigilante me contó que, por la década de los 8() , los galos de monte eran comunes en la UCA; él vio peléandose a dos de ellos... Pero la mano inclemente fue acabando con ellos: un día, un trabajador de mantenimiento de la universidad encontró en un tragante varios cachorritos de galo de monte; ni corto ni perezoso fue a venderlos por unos cuantos pesos. Fueron los áltimos animalitos de la especic que el mencionado vigilante vio por ahí.

Ahora bien, todavía se ven en el paredón aquel algunas cuevas que parecen estar aún habitadas y en uso (se ven redondeadas y libres de monte). Como si quisicran demostrar a lodo el mundo: "-Estamos empeñados en seguir viviendo ahi; a pesar de los intentos de ustedes por expulsarnos".

Los conejos silvestres lambién fueron numerosos en la UCA, hasta finales de los 80. Durante las vacaciones, período en que el campus permanece cerrado, yo veía correlear a varios de esos animalitos. Parece que tenían sus cuevas debajo del edilicio de la biblioteca... Pero la presencia de perros y gatos, junto con la cacería lurtiva, dieron cuenta de los últimos conejos silvestres. En la aclualidad, las ardillas son los mamileros silvestres mayormente represenlados (los lacuacines son asiduamente perseguidos por algunos trabajadores de mantenimiento; y mucho me lemo que ya están acabando con esos simpálicos marsupiales.)

En suma, la impresión que uno liene es la siguiente: si el ser humano no melicra la mano, si dejara a la naluraleza librada a sus propios medios, el país 
entero se repoblaría de árboles y de animales. Pero si el hombre se empeña en lo contrario, en aniquilar sistemáticamente toda forma de vida natural; entonces puede que ese ser humano consiga convertir a El Salvador en una patćlica "naluraleza muerta", porque para encontrar a los seres silvestres va a tener que recurrirse a las fotos, videos o pintura. "- Háblele a sus hijos de cómo es el torogoz, porque dentro de pocos años ese animalito ya no va a existir sino en álbumes y en folografías", podría ser un eslogan aplicable a todos los seres silvesıres del país.

Al menos, todavía no han logrado del todo su empeño esos salvadoreños de las últimas promociones, y lo que sí han hecho es ir desplazando cada vez. mas lejos de su territorio "humanizado" a esos seres "salvajes". La frontera entre la "gran ciudad" y el "monte" se va acentuando y agrandando, pero — menos malen las zonas de alta concentración urbana (ya volveremos sobre ello).

La muestra de esa tozuda voluntad de renovación vilal frente a la no menos tozuda voluntad de destrucción, podemos encontrarla aún en muchos puntos y lugares del país ( los parques naturales serian como los más notorios: Montecristo, El Imposible, el Parque Deinninger, elcétera.) Pero hay uno en particular que a mí siempre me ha llamado la atención de manera especial... En los alrededores de Olocuilta hay unos farallones que le salen a uno al paso, si se viaja hacia el aeropuerto de Comalapa o hacia la Costa del Sol... pues bien, durante el verano, esos paredones lucen pelados, sin vida. Desde luego, la mano inclemente del campesino de la zona se ha encargado de quemar todo rastro de vida vegetal. Tierra árida, peñascos al aire y un sol achicharrante (ya se siente Comalapa: el comal ardiente) serían suficiente para atesliguar que ahí no hay ya vida y que eso es un adelanto del desierto que puede ser en un fuluro próximo el suclo salvadoreño...

Pero otra cara se le ve a esos mismos farallones durante la ćpoca de lluvias: entonces, los peñascos se cubren de plantas, y yo no sé de dónde le salen hasta árboles grandes. De modo que ahí pareciera haber sido siempre trópico permanentemente reverdecido, lujo y exceso de todos los tonos del verde: "-Ya ves, Lito, me recuerda el amigo Óscar Edgardo cuando pasamos por ahí-: si dejáramos al país a su propia suerte, él se encargaría de vestirse de este hermoso follaje. iiii Necios nosotros que, año con año, nos empeñamos en desnudarlo!!!

Hace unas semanas, estuvimos con la familia Melhado visitando San Esteban Catarina, un pueblo cercano a la ciudad de San Vicente. Fascinados, adultos y nin̄os recorrimos la zona; descendimos al Iloyo Caldera, un cráler apagado, de unos $2 \mathrm{Km}$. de diámetro y de unos $200 \mathrm{~m}$ de profundidad. Según Sergio, la persona que nos inviló a visitar el lugar, la leyenda cuenta que una bruja tomó el agua que antes había en ese cráter, la echó en una cáscara de huevo, y fue luego a depositarla en otro hoyo (lambién cráter volcánico): así fue como nació la Laguna Bruja, llamada así en memoria de aquel hecho legendario... También 
visitamos dicha laguna, y todos gozamos bañándonos y retozando en acpucllis aguas frescas y medicinales.

Los excursionistas nos dimos gusto recorriendo de arriba abajo las lomils que rodean San Esteban Catarina, y recogiendo plantas y flores como lia quichracántaros, platanillos silvestres y otras. La sensación que uno tiene des pués de esa experiencia es la de haber estado en otro país, en otro mundo... $\wedge$ pesar de lo cerca que está de la ciudad de San Vicente y de lo próximo al "grall San Salvador", pareciera que no tiene nada que ver lo uno (el campo) con lı otro (la ciudad). Claro, lo que se ha ido dando en El Salvador es la alta concen tración urbana, con el consiguiente "abandono" del campo; de modo que en in! reducidisimo espacio (San Salvador y su periferia) se aglomeran alrededor de ? millones y medio de personas. No es de extrañar, entonecs, que las colonias y suburbios que conforman esa 7.ona se parezcan cada vez. más a colmenas (Sill Bartolo lo parece, con sus ordenadas hileras de casitas-celdas) o, peor aún, a termiteros (con sus recovecos y callejuclas retorcidas: eso parecen ('iudad Delgado, o Soyapango). En todo caso, el hacinamiento, el ruido y la basura omnipresentes, parecen ya elementos connaturales de un país que esta siendo discñado a la medida de los caóticos, anticstéticos, anticcológicos y antitodo proyectos de sus "discñadores".

Por eso, en la misma medida en cue crece la ciudad, crecen aquellos espacios "intocados": alla donde no llega el bullicio ni los alanes de la gran ciudad; donde corre libre el viento, y puede oírse el silbo de la codorniz (por cierto, oi muchas de esas aves, ocultas entre los maizales y los lirijolares). De alla de esos lugares uno retorna renovado, oxigenado, con el optimismo (como un último asidero para la esperanza) de que no todo está perdido, de que aún es posible restituir el ritmo cardiaco sano del país, aunque sean necesarios la respiración boca a bocal o algún choque eléctrico

Quiero terminar esta parte "probatoria" de las energías vitales que aún circulan en este país, trayendo a cuento algo que me ocurrió hace pocas semanas: platicaba yo con Julio -la persona que cuida el terreno de los Melhado, en la Costa del Sol- frente al apartamento donde estaba yo alojado. Ya eran como las seis de la tarde, así que costaba distinguir las cosas a la simple luz. natural... Enfrascado como estaba en la conversación, sólo logró distracrme una silueta sospechosa; di un respingo porque cré ver una avispa grande - de las ahorcadoras, como las llaman- y hasta luve la intención de tirar un manotazo para alcjar al peligroso insecto. Pero me contuve, pues se me cruzó al instante la idea de que, más bien, podria tratarse de una papalota o mariposa nocturna.

Seguí platicando, sentado en el borde de unos $40 \mathrm{~cm}$ de alto que rodea al apartamento... Y entonces pasó de nuevo el animalito, revoloteando entre las icsoras que crecen en un arríate. Caí de pronto en la cuenta de qué animal era 
realmente: se trataba de un colibrí pequeñisimo, delgado el cuerpo como el de una avispa y diminulas las alas como las de una papalola más bien pequeña.

“- ¡Julio, si égite es un pájaro... un colibrí que anda chupíndole la micl a esass flores de icsora!" "Sí — me di jo Julio-, por aquí sabe venir seguido este pajarito ..."

A pesar de la rapidez del vuelo y de la poca visibilidad que había, yo pude distinguir al colibri; lenía alas negras, al ravesadas por una rayila amarilla, y su cabeza era del porte de un pequeño botón. “- ¡Con razón le llaman el pájaro mosca - le comenté a Julio-; aunque más parece un abejorro!" De Iodas maneras, a esal delicadeza de la naluraleza se le conoce también como "joya alada"; cierlamente lo es... ¡Y pensar que en El Salvador aún pueden verse esos relinamientos con que nos sorprende de vez en cuando la naluralcza! 